\title{
Brazilin Isolated from Caesalpinia sappan Suppresses Nuclear Envelope Reassembly by Inhibiting Barrier-to-Autointegration Factor Phosphorylation
}

\author{
Seong-Hoon Kim, Ha-Na Lyu, Ye Seul Kim, Yong Hyun Jeon, Wanil Kim, Sangjune Kim, \\ Jong-Kwan Lim, Ho Won Lee, Nam-In Baek, Kwan-Yong Choi, Jaetae Lee, and \\ Kyong-Tai Kim \\ Department of Life Sciences (S.-H.K., H.-N.L., Y.S.K., W.K., S.K., K.-T.K.), Division of Integrative Biosciences and Biotechnology \\ (J.-K.L., K.-Y.C., K.-T.K.), Pohang University of Science and Technology, Pohang, South Korea; Graduate School of \\ Biotechnology and Plant Metabolism Research Center, Kyung-Hee University, Suwon, South Korea (N.-I.B.); and Department of \\ Nuclear Medicine, Kyungpook National University School of Medicine, Daegu, South Korea (Y.H.J., H.W.L., J.L.)
}

Received August 3, 2014; accepted October 31, 2014

\section{ABSTRACT}

To date, many anticancer drugs have been developed by directly or indirectly targeting microtubules, which are involved in cell division. Although this approach has yielded many anticancer drugs, these drugs produce undesirable side effects. An alternative strategy is needed, and targeting mitotic exit may be one alternative approach. Localization of phosphorylated barrierto-autointegration factor (BAF) to the chromosomal core region is essential for nuclear envelope compartment relocalization. In this study, we isolated brazilin from Caesalpinia sappan Leguminosae and demonstrated that it inhibited BAF phosphorylation in vitro and in vivo. Moreover, we demonstrated direct binding between brazilin and BAF. The inhibition of BAF phosphorylation induced abnormal nuclear envelope reassembly and cell death, indicating that perturbation of nuclear envelope reassembly could be a novel approach to anticancer therapy. We propose that brazilin isolated from $C$. sappan may be a new anticancer drug candidate that induces cell death by inhibiting vaccinia-related kinase 1-mediated BAF phosphorylation.

\section{Introduction}

Drugs that depolymerize and stabilize microtubules, including vinca alkaloids (vinblastine and vincristine) and taxanes (paclitaxel/taxol and docetaxel), have long been used to treat cancer (Jordan and Wilson, 2004; Dumontet and Jordan, 2010). In addition to their anticancer effects, however, these drugs cause various side effects. To avoid this problem, researchers have attempted to develop drugs that indirectly target microtubules via microtubule regulator proteins, such as polo-like kinase 1 (Plk1), Aurora A and B, and Eg5 (Blangy et al., 1995; Carmena and Earnshaw, 2003; Barr et al., 2004). However, some cancer cells that are treated with these drugs skip mitotic arrest and survive as a result of adaptation or mitotic slippage in which the spindle assembly checkpoint does not activate cell cycle arrest after chromosomal segregation, resulting in the maintenance of aneuploidy (Rieder and

This work was supported by grants from the National Research Foundation of Korea (NRF) [Grant 2013-056085, 2014R1A2A2A01002931]; the NextGeneration BioGreen 21 Program [No. PJ00950301] funded by the Korean Rural Development Administration; and the BK21 Plus program [Grant 10Z20130012243] funded by the Korean Ministry of Education.

dx.doi.org/10.1124/jpet.114.218792.

S This article has supplemental material available at jpet.aspetjournals.org.
Maiato, 2004; Brito and Rieder, 2006). Thus, rather than targeting spindle assembly, an alternative strategy of targeting mitotic exit has been proposed (Manchado et al., 2012). In contrast to strategies that rely on microtubule disruption, directly targeting mitotic exit does not promote adaptation or mitotic slippage. Therefore, if cancer cells are damaged at mitotic exit, they cannot escape death. To date, however, drugs that target mitotic exit have not been commonly used.

To complete mitotic exit, nuclear membrane reformation and cytokinesis must take place. Nuclear envelope reassembly is a phenomenon in which the nuclear membrane and associated proteins, such as barrier-to-autointegration factor (BAF), LEM-domain proteins (LAP2, emerin, and MAN1), lamin, and nuclear pore complex, relocate around separated chromosomes during telophase (Haraguchi et al., 2001; Dechat et al., 2004). BAF is the first of the nuclear membrane-associated proteins to be recruited to the core region, the central region of the assembling nuclear rim near spindle microtubules during nuclear envelope reformation (Haraguchi et al., 2008). Relocalization of BAF into the core region of chromosomes leads to recruitment of other nuclear membrane-anchored proteins and nuclear envelope transmembrane proteins. Therefore, BAF is key in controlling the escape of dividing cells from mitotic exit. Phosphorylated

ABBREVIATIONS: BAF, barrier-to-autointegration factor; DMSO, dimethylsulfoxide; DsRed, Discosoma fluorescent red; EtOAc, ethyl acetate; GFP, green fluorescent protein; IR, infrared; MS, magnetic spectrometry; PBS, phosphate-buffered saline; TUNEL, terminal deoxynucleotidyl transferase-mediated digoxigenin-deoxyuridine nick-end labeling; VRK1, vaccinia-related kinase 1. 
residues of vaccinia-related kinase 1 (VRK1), a unique upstream kinase of BAF, are involved in the dissociation of chromosomes from the nuclear envelope at mitosis onset and nuclear envelope reformation at the end of mitosis (Nichols et al., 2006; Haraguchi et al., 2008). In Caenorhabditis elegans embryos, depletion of the VRK1 homolog abolishes targeting of the BAF-1 homolog to the core-like region and prevents nuclear envelope reformation (Gorjanacz et al., 2007). Indeed, BAF phosphorylation by VRK1 is required for nuclear envelope reassembly, although the process is so complex that the detailed molecular mechanism remains elusive.

We hypothesized that inhibition of VRK1-mediated BAF phosphorylation might trigger severe cell cycle defects because BAF phosphorylation is essential for nuclear envelope reassembly. To identify novel inhibitors of BAF phosphorylation, we screened a natural herb library. To date, natural products have been used to develop new treatments for many diseases. Plants contain a variety of metabolites for defense, communication, and predation, some of which have anticancer effects (Cragg et al., 2009). As a result, more than $70 \%$ of commercial anticancer drugs have been derived from or inspired by natural products (Gordaliza, 2007; Cragg et al., 2009).

Our screen revealed that Caesalpinia sappan extract inhibited VRK1-mediated BAF phosphorylation. Subsequently, brazilin was isolated from the extract as a BAF inhibitor. C. sappan heartwood has been used as a traditional medicine for various diseases. Brazilin, one of the main C. sappan components (Puchtler et al., 1986), is reported to possess various biologic effects, including anti-inflammatory activity (Hikino et al., 1977; Bae et al., 2005), antihepatotoxicity activity (Moon et al., 1992), induction of immunologic tolerance (Choi and Moon, 1997; Mok et al., 1998), inhibition of downstream cAMP signaling (Won et al., 2004), inhibition of protein kinase $\mathrm{C}$ and insulin receptor kinase (Kim et al., 1998), and antiplatelet activity (Hwang et al., 1998). Indeed, its cytotoxic properties as an antitumor agent have previously been reported (Kim et al., 2012). However, the detailed molecular mechanisms underlying these properties are unclear.

In this study, we isolated brazilin from C. sappan after screening a natural herb library for inhibitors of VRK1mediated BAF phosphorylation. We found that (1) brazilin inhibited BAF phosphorylation by VRK1 in vitro and in vivo and (2) the abrogation of BAF phosphorylation is the result of direct binding between $\mathrm{BAF}$ and brazilin. Brazilin-mediated inhibition of $\mathrm{BAF}$ phosphorylation triggers a defect in nuclear envelope reassembly at the onset of telophase, eventually resulting in cell death. The anticancer effect of brazilin was also validated in vivo. On the basis of these results, we propose that brazilin should be considered a candidate for a new class of anticancer drugs that target mitotic exit.

\section{Materials and Methods}

\section{General Experimental Procedures}

Optical rotation was measured using a JASCO P-1020 polarimeter (Jasco Analytical Instruments, Easton, MD). The infrared (IR) spectrum was obtained with a Spectrum GX FT-IR spectrometer (PerkinElmer Life and Analytical Sciences, Waltham, MA). Electron ionization-magnetic spectrometry (MS) spectra were obtained with an Agilent 7890A-5975C GC/MSD system (Agilent Technologies,
Santa Clara, CA). The $\left[{ }^{1} \mathrm{H}\right] \mathrm{NMR},\left[{ }^{13} \mathrm{C}\right] \mathrm{NMR}$, distortionless enhancement by polarization transfer, correlation spectroscopy, heteronuclear multiple-bond correlation, and heteronuclear multiple-quantum correlation NMR spectra were obtained with a Bruker DRX-500 Fourier transform-NMR spectrometer (Bruker Corporation, Bruker, Billerica, MA). The internal standard, methanol- $d_{4}$ with trimethoxysilane, was purchased from Sigma-Aldrich (St. Louis, MO). Merck silica gel 60 $(63-200 \mu \mathrm{m})$ was used for column chromatography. Analytical thinlayer chromatography was performed using Merck silica gel 60 F-254 and silica gel 60 RP-18 F-254 thin-layer chromatography plates. Spots were detected by UV light ( 254 and $365 \mathrm{~nm}$ ) and by spraying with $10 \%$ $\mathrm{H}_{2} \mathrm{SO}_{4}$ and heating on a hot plate.

\section{Reagents}

Lamin B, glyceraldehyde 3-phosphate dehydrogenase, and glutathione $S$-transferase antibody were purchased from Santa Cruz Biotechnology (Santa Cruz, CA) and histone H3 phospho-Ser10 antibody was purchased from Abcam (Cambridge, UK) and those against histone $\mathrm{H} 3$, phospho-cAMP response element-binding protein and cAMP response element-binding protein were obtained from Cell Signaling Technology (Danvers, MA). VRK1 antibody was generated in rabbit, and phospho-BAF antibody was a gift from Robert Craigie, US National Institutes of Health. Hoechst 33342 stain and CNBrSepharose 4B were purchased from Sigma-Aldrich.

\section{Plant Material}

C. sappan wood was purchased from an oriental drug store in Pohang, Gyeongbuk, South Korea, in May 2010. A voucher specimen (CS2010-01) is being kept at the Laboratory of Molecular Neurophysiology, Postech, Pohang, South Korea.

Extraction and Isolation. The dried wood of C. sappan $(4.2 \mathrm{~kg})$ was extracted twice with ethyl acetate (EtOAc; 20 l) at room temperature and filtered (Adventec filter paper no. 2; Adventec, Ehime, Japan). The extract was obtained by concentration under reduced pressure. The EtOAc extract $(29.6 \mathrm{~g})$ was subjected to chromatography over silica gel $(7.5 \times 15 \mathrm{~cm})$ and eluted with a chloroform-methanol gradient $(8: 1,6: 1$, and $3: 1)$ to produce 10 fractions (CSE1-CSE10). Fraction CSE7 (1.25 g) was subjected to silica gel column chromatography $(4.5 \times 14 \mathrm{~cm})$ and eluted with $n$-hexane-EtOAc $(2: 3,1: 2)$ to obtain compound 1 (125 mg).

Characterization of Brazilin. Brazilin was characterized by comparing NMR spectrometry, MS, and IR spectrometry results with literature values (Baek et al., 2000). Brazilin (7,11b-dihydroindeno [2,1-c]chromene-3,6a,9,10(6H)-tetrol): pale-yellow crystals. IR ( $\mathrm{KBr}$, $\mathrm{cm}^{-1}$ ): 3378, 2915, 2850, 1615, 1510, 1465; electron ionization-MS m/z: $286[\mathrm{M}]+, 268\left[\mathrm{M}-\mathrm{H}_{2} \mathrm{O}\right]+, 267\left[\mathrm{M}-\mathrm{H}-\mathrm{H}_{2} \mathrm{O}\right]+, 229 ;{ }^{1} \mathrm{H}-\mathrm{NMR}(500 \mathrm{MHz}$, CD3OD, $\delta): 7.20\left({ }^{1} \mathrm{H}, \mathrm{d}, \mathrm{J}=8.5, \mathrm{H}-1\right), 6.73\left({ }^{1} \mathrm{H}, \mathrm{s}, \mathrm{H}-8\right), 6.62\left({ }^{1} \mathrm{H}, \mathrm{s}\right.$, $\mathrm{H}-11), 6.49\left({ }^{1} \mathrm{H}, \mathrm{dd}, \mathrm{J}=8.5,2.5 \mathrm{~Hz}, \mathrm{H}-2\right), 6.32\left({ }^{1} \mathrm{H}, \mathrm{d}, \mathrm{J}=2.5 \mathrm{~Hz}, \mathrm{H}-4\right)$, $3.99\left({ }^{1} \mathrm{H}\right.$, br. second, H-12), $3.95\left({ }^{1} \mathrm{H}\right.$, dd, J = 11.0, $\left.1.0 \mathrm{~Hz}, \mathrm{H}-6 \mathrm{a}\right), 3.71$ $\left({ }^{1} \mathrm{H}, \mathrm{d}, \mathrm{J}=11.0 \mathrm{~Hz}, \mathrm{H}-6 \mathrm{~b}\right), 3.04\left({ }^{1} \mathrm{H}, \mathrm{d}, \mathrm{J}=15.5 \mathrm{~Hz}, \mathrm{H}-7 \mathrm{a}\right), 2.79\left({ }^{1} \mathrm{H}, \mathrm{d}\right.$, $\mathrm{J}=15.5 \mathrm{~Hz}, \mathrm{H}-7 \mathrm{~b}) ;{ }^{13} \mathrm{C}-\mathrm{NMR}(125 \mathrm{MHz}, \mathrm{CD} 3 \mathrm{OD}, \delta): 157.8\left(\mathrm{C}-4^{\prime}\right)$, 155.7 (C-3), 145.6 (C-9), 145.3 (C-10), 137.4 (C-11'), 132.2 (C-1), 131.3 (C-7'), 115.5 (C-1'), 112.9 (C-8), 112.4 (C-11), 109.9 (C-2), 104.3 (C-4), 78.1 (C-6'), 70.8 (C-6), 51.0 (C-12), 42.9 (C-7).

Plasmids, Recombinant Protein Purification. To generate the BAF and VRK1 expression constructs, the full-length $B A F$ and VRK1 genes were amplified from HeLa cells using the polymerase chain reaction. Each amplicon was cloned into phospho-enhanced green fluorescent protein-C1, phospho-Discosoma fluorescent red (DsRed)-Monomer-N1, and pProEX (Clontech, Takara Bio, Shiga, Japan). To purify recombinant glutathione $S$-transferase-VRK1, HisVRK1, and His-BAF, Escherichia coli strain BL21 was transformed with pGEX-4T-3-VRK1, pProEX-VRK1, or pProEX-BAF and expressed proteins were purified using Ni-NTA beads (Invitrogen/Life Technologies, Carlsbad, CA). 


\section{Cell Culture and Transfection}

The A549 and SH-SY5Y cells were cultured in RPMI 1640 and Dulbecco's modified Eagle's medium-high-glucose media, respectively (HyClone Laboratories, Logan, UT) containing 10\% fetal bovine serum (HyClone) and 1\% penicillin/streptomycin (Welgene, Daegu, South Korea) in a humidified $5 \% \mathrm{CO}_{2}$ incubator at $37^{\circ} \mathrm{C}$. Transient transfection was performed using an MP-100 microporator (Invitrogen/Life Technologies), according to the manufacturer's instructions.

\section{Terminal Deoxynucleotidyl Transferase-Mediated Digoxigenin-Deoxyuridine Nick-End Labeling Assay}

A549 cells were transfected with DsRed-N1-monomer-BAF or, in the case of controls, not transfected. Cells were grown on glass chips coated with poly-D-lysine (Sigma-Aldrich) and then treated with brazilin $(100 \mu \mathrm{M})$ for different times. Cells were fixed with $4 \%$ paraformaldehyde, permeabilized, and stained with Hoechst stain and the DeadEnd Fluorometric terminal deoxynucleotidyl transferase-mediated digoxigenin-deoxyuridine nick-end labeling (TUNEL) system kit (Promega, Madison, WI), according to the manufacturer's instructions.

\section{Protein Kinase Assay and Immunoblotting}

An in vitro kinase assay was performed in accordance with methods previously described elsewhere (Kim et al., 2013). In brief, an in vitro kinase assay was performed with His-VRK1 and its substrates, including His-BAF and His-H3 histone, in kinase buffer (50 mM 3-Nmorpholino)propanesulfonic acid, $\mathrm{pH} 7.2,25 \mathrm{mM} \beta$-glycerophosphate, $10 \mathrm{mM}$ EGTA, $4 \mathrm{mM}$ EDTA, $50 \mathrm{mM} \mathrm{MgCl}, 0.5 \mathrm{mM}$ dithiothreitol) containing $\left[\gamma_{-}{ }^{32} \mathrm{P}\right]$ ATP (PerkinElmer) or ATP (Sigma-Aldrich). The kinase assay mixtures were incubated at $30^{\circ} \mathrm{C}$ for 30 minutes. Radioactivity incorporation was detected by autoradiography, and phosphorylation of His-H3 histone was analyzed by immunoblotting. The quantities of proteins used in kinase assays were measured by using silver nitrate (Sigma-Aldrich) or immunoblotting. Immunoblot analysis was performed as we previously described elsewhere (Park et al., 2011). For immunoblot analysis, bands were visualized using the Western blot detection kit (Neuronex, Pohang, South Korea).

\section{Luteolin-Sepharose 4B Preparation and In Vitro Pull-Down Assay}

CNBr-sepharose 4B bead powder was suspended in activation solution for coupling reaction. Activated Sepharose 4B beads were incubated in coupling solution with brazilin on a rotary shaker at $4^{\circ} \mathrm{C}$ overnight. For the in vitro pull down assay, His-BAF or A549 cell lysates transfected with green fluorescent protein (GFP)-BAF were incubated with brazilin-Sepharose $4 \mathrm{~B}$ beads in reaction solution for 12 hours. Proteins bound to the beads were analyzed by immunoblotting. Immnunoblotting was performed by using indicated antibodies and following the detailed procedures described previously (Byun et al., 2010).

\section{Surface Plasmon Resonance}

BAF was immobilized on a carboxymethyl dextran hydrogel surface sensor chip (Reichert Technologies, Depew, NY) using a $10 \mathrm{mM}$ sodium acetate, $\mathrm{pH} 5.0$ immobilization buffer. The ligand was prepared. Kinetic titration was performed using a running buffer of

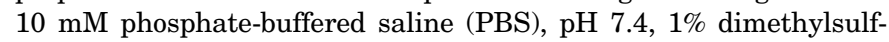
oxide (DMSO). Analysis of the collected data were performed by scrubber2 software (BioNavis, Tampere, Pirkanmaa, Finland).

\section{Confocal Microscopy}

A549 cells transfected with DsRed-N1-monomer-VRK1 or GFP$\mathrm{BAF}$ were grown on a chip, and then treated with $50 \mu \mathrm{M}$ brazilin for
12 hours. Cells were fixed with paraformaldehyde, permeabilized in PBS with $10 \%$ fetal bovine serum, and stained with Hoechst. Cells were observed using confocal microscopy.

\section{Immunocytochemistry}

The A549 cells were grown on a chip and then treated with $50 \mu \mathrm{M}$ brazilin for 12 hours. Cells were fixed with paraformaldehyde permeabilized in PBS with $10 \%$ fetal bovine serum, and stained with lamin B antibody (Santa Cruz Biotechnology) and Hoechst. Cells were observed using confocal microscopy. We calculated the cells to show diffused lamin B in cytosol of HeLa cells. Data represent the mean of three independent experiments \pm S.E.M. Each experiment has at least three samples, and each sample had at least 50 cells.

\section{Flow Cytometry}

Cells were fixed with $70 \%$ ethanol containing $0.4 \%$ Tween 20 . Cellular DNA was stained with $50 \mu \mathrm{g} / \mathrm{ml}$ propidium iodide (Fluka, Buchs, Switzerland) and $100 \mu \mathrm{g} / \mathrm{ml}$ RNase A (Sigma-Aldrich) in PBS. Samples containing 5000 cells were analyzed using a FACS Calibur System (BD Biosciences, Franklin Lakes, NJ).

\section{Mouse Experiment}

We randomly assigned 4-week-old athymic Balb/c nude male mice weighing $20 \mathrm{~g}$ into the following groups: 20 and $40 \mathrm{mg} / \mathrm{kg}$ brazilin $(n=$ 3 per group), and control $(n=2)$. Each mouse was injected subcutaneously with A549-FIG cells $\left(5 \times 10^{6}\right.$ cells/mouse). When tumor size reached to $\sim 5 \mathrm{~mm}$ in diameter, mice were intratumorally treated with 20 and $40 \mathrm{mg} / \mathrm{kg}$ brazilin, or $10 \%$ DMSO in PBS twice a week. Treatment continued for 2 weeks. Tumor growth was monitored using both in vivo bioluminescence imaging and tumor volume measurement with caliper (length $\times$ width $\times$ height $\times 0.52$ ).

Bioluminescence imaging was performed using the IVIS Lumina II (Caliper Life Sciences, Hopkinton, MA), which included a highly sensitive charge-coupled device camera mounted on a light-tight specimen chamber. The D-luciferin potassium salt (Caliper Life Sciences) was diluted to $3 \mathrm{mg} / 100 \mu \mathrm{l}$ in PBS before use, and the mice were injected intraperitoneally with $100 \mu \mathrm{l}$ of this D-luciferin solution. After 10 minutes, the mice were placed individually in the specimen chamber and then were measured with light emitted by luciferase. Grayscale photographic images and bioluminescent color images were superimposed using LIVINGIMAGE, version 2.12 (Xenogen, Alameda, CA), and IGOR image analysis FX software (WaveMetrics, Lake Oswego, OR). Bioluminescence signals were expressed in units of photons per $\mathrm{cm}^{2}$ per second per steradian $\left(\mathrm{P} / \mathrm{cm}^{2} / \mathrm{s} / \mathrm{sr}\right)$. To quantify emitted light, regions of interest were drawn over the tumor region, and total photon effluxes over an exposure time of 1 second were determined.

\section{Results}

Characterization of Brazilin from C. sappan. VRK1 is the sole BAF kinase identified to date. As natural compounds have long been used to develop new drugs, we screened a library composed of hundreds of natural product extracts to identify a small molecule inhibitor of VRK1-mediated BAF phosphorylation (data not shown). A fraction isolated from C. sappan L. significantly inhibited VRK1-mediated BAF phosphorylation in vitro (data not shown). Thus, we hypothesized it must contain an inhibitor of VRK1-mediated BAF phosphorylation. Next, we attempted to isolate the putative VRK1 inhibitor from C. sappan (Supplemental Fig. 1). NMR spectrometry, MS, and IR spectrometry results indicated that the compound isolated was brazilin (Fig. 1, A-C). 
Brazilin Inhibits VRK1-Mediated Phosphorylation of BAF. To determine whether brazilin isolated from $C$. sappan inhibits VRK1-mediated phosphorylation of BAF, we performed an in vitro kinase assay using purified BAF and VRK1. Administration of between 3 and $10 \mu \mathrm{M}$ of brazilin dramatically reduced BAF phosphorylation. The half maximal inhibitory concentration $\left(\mathrm{IC}_{50}\right)$ was estimated to be approximately $5 \mu \mathrm{M}$ (Fig. 2A). This indicates that $C$. sappan brazilin is an effective inhibitor of VRK1-mediated BAF phosphorylation in vitro. By contrast, brazilin had no effect on VRK1 autophosphorylation (Fig. 2A). This indicates that brazilin does not directly inhibit VRK1 and is instead

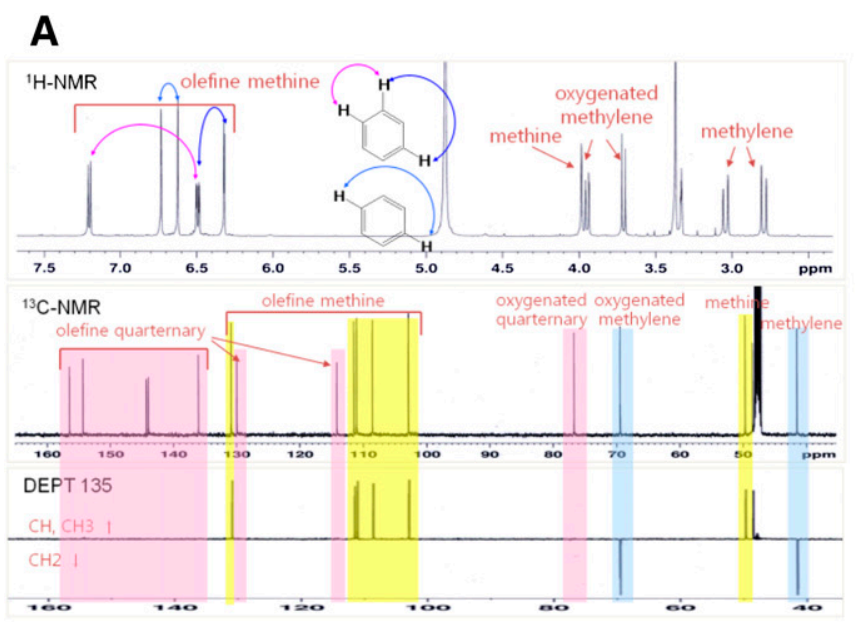

B
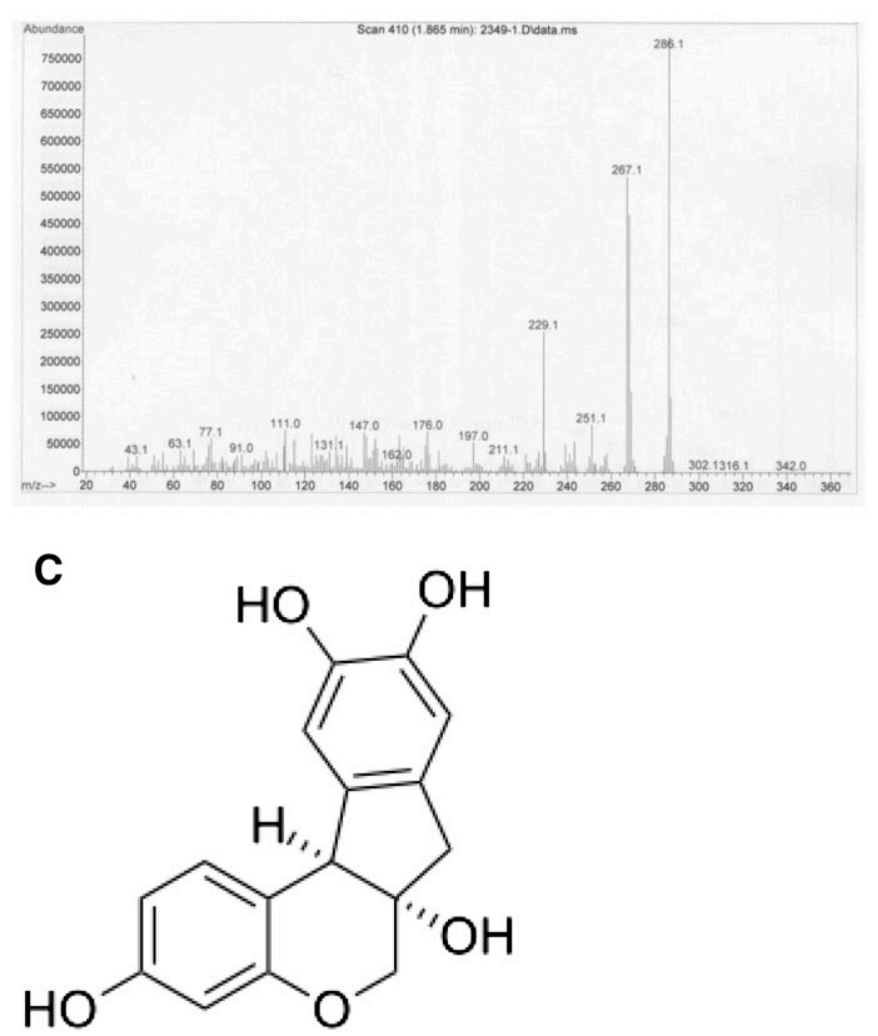

Fig. 1. Brazilin was isolated from C. sappan. (A) Brazilin $\left[{ }^{1} \mathrm{H}\right] \mathrm{NMR}$ and $\left[{ }^{13} \mathrm{C}\right]$ NMR data. (B) Brazilin MS data. (C) Chemical structure of brazilin. a specific inhibitor of VRK1-mediated BAF phosphorylation. Additionally, we found that brazilin did not affect VRK1mediated H3 phosphorylation (Fig. 2B; Supplemental Fig. 2). These data indicate that $C$. sappan brazilin specifically inhibits BAF in vitro.

Endogenous and ectopic VRK1 expression is localized in the nucleus (Lopez-Borges and Lazo, 2000; Nichols and Traktman, 2004; Sevilla et al., 2004a,b), as is ectopic BAF expression (Segura-Totten et al., 2002; Shimi et al., 2004). However, ectopic BAF expression can be transiently relocalized into the cytosol when VRK1 is coexpressed with BAF (Nichols et al., 2006). Relocation of BAF into the cytosol does not occur 1) when VRK1 is coexpressed with a BAF mutant that cannot be phosphorylated or 2) when a VRK1 catalytic null mutant is coexpressed with ectopic BAF (Nichols et al., 2006). These results indicate that VRK1-mediated BAF phosphorylation determines the location of ectopically expressed BAF. Thus, by observing the location of ectopically expressed BAF, we could infer whether VRK1-mediated BAF phosphorylation occurred.

We used brazilin to treat cells in which DsRed-VRK1 was coexpressed with GFP-BAF. Rather than being found in the cytosol, GFP-BAF was located in the nucleus (Fig. 2C; Supplemental Fig. 3A). The nuclear location of BAF in cells treated with brazilin indicates that VRK1-mediated BAF phosphorylation did not occur (Fig. 2C, bottom). Treatment with DMSO resulted in the relocation of BAF into the cytosol, indicating that GFP-BAF was phosphorylated by ectopically expressed VRK1 under these conditions. To confirm the inhibition of BAF phosphorylation by brazilin, we performed an immunoblotting assay. Brazilin treatment expectably reduced BAF phosphorylation in A549 cells (Supplemental Fig. 3B). These data show that brazilin inhibits VRK1mediated BAF phosphorylation, supporting brazilin as a candidate inhibitor of BAF phosphorylation.

Brazilin Binds Specifically to BAF. To be an effective BAF phosphorylation inhibitor, brazilin should bind specifically to BAF. Therefore we investigated whether brazilin interacts directly with BAF. First, we performed a pull-down assay to demonstrate binding between BAF and VRK1 in vitro. Sepharose-4B beads were conjugated to the hydroxylgroup of brazilin, and the brazilin-conjugated beads were incubated with lysate of cells that overexpressed BAF. Control beads that were not conjugated to brazilin did not interact with $\mathrm{BAF}$, and brazilin-conjugated beads bound to GFP-BAF but not to GFP (Fig. 3A). This suggests that brazilin formed a complex with the BAF present in the cell lysate.

However, as other proteins in the cell lysate could also potentially form a complex with BAF, it was possible that the BAF-brazilin interaction resulted from indirect binding. To exclude this possibility, we conducted another pull-down assay using recombinant BAF (Fig. 3B). When recombinant $\mathrm{BAF}$ was incubated with brazilin-conjugated beads, $\mathrm{BAF}$ was pulled down; however, no BAF was detected in association with control beads. This suggests that brazilin interacts directly with recombinant BAF.

Next, we measured the strength of the interaction between brazilin and BAF using surface plasmon resonance (Fig. 3C). We immobilized recombinant BAF on the surface of a gold chip, and then allowed brazilin to flow over the chip, from low to high concentration. This kinetic titration method can perform as robustly as the classic injection method (Karlsson 
A

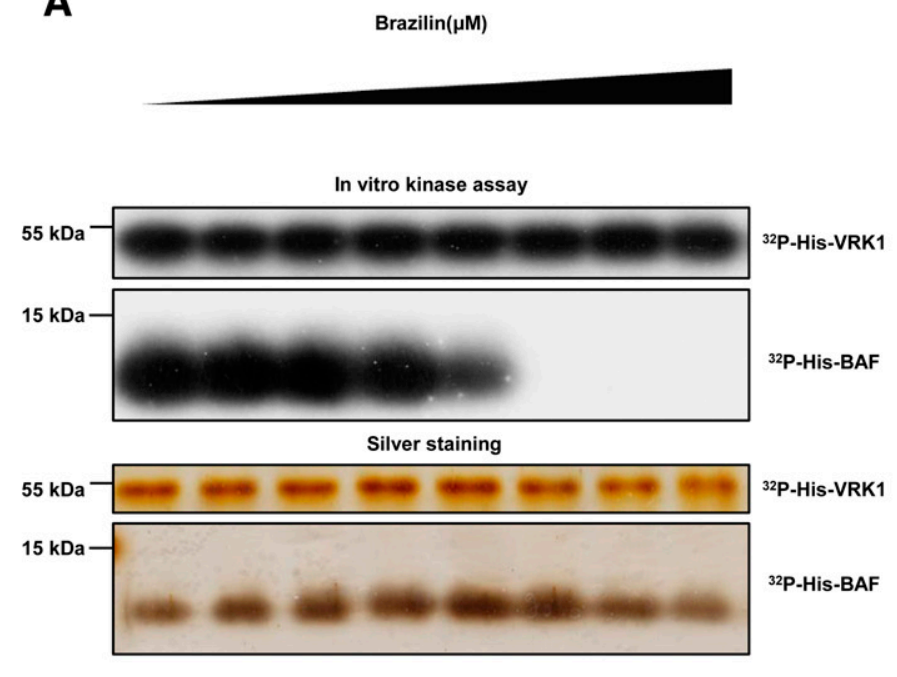

C

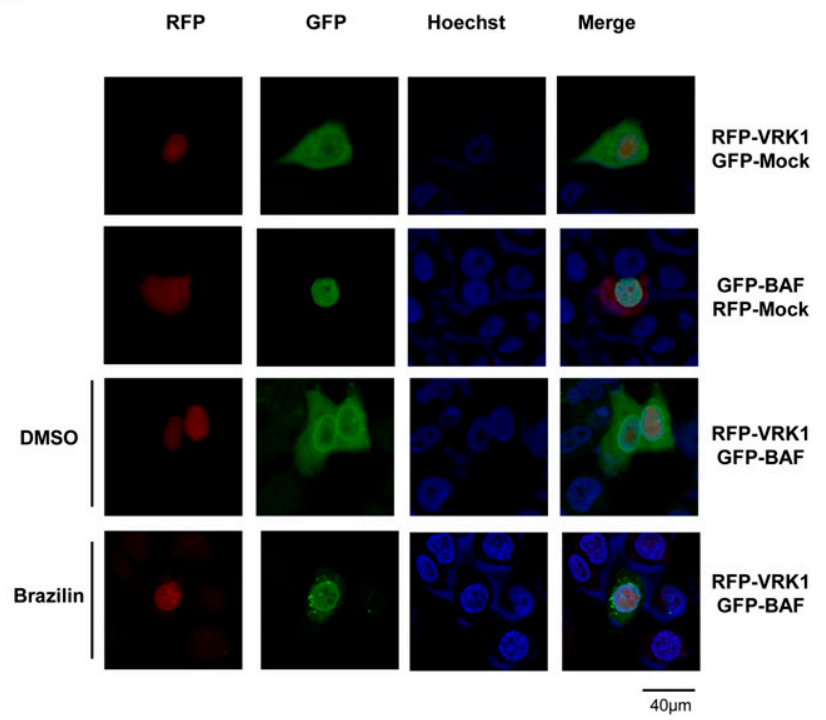

B
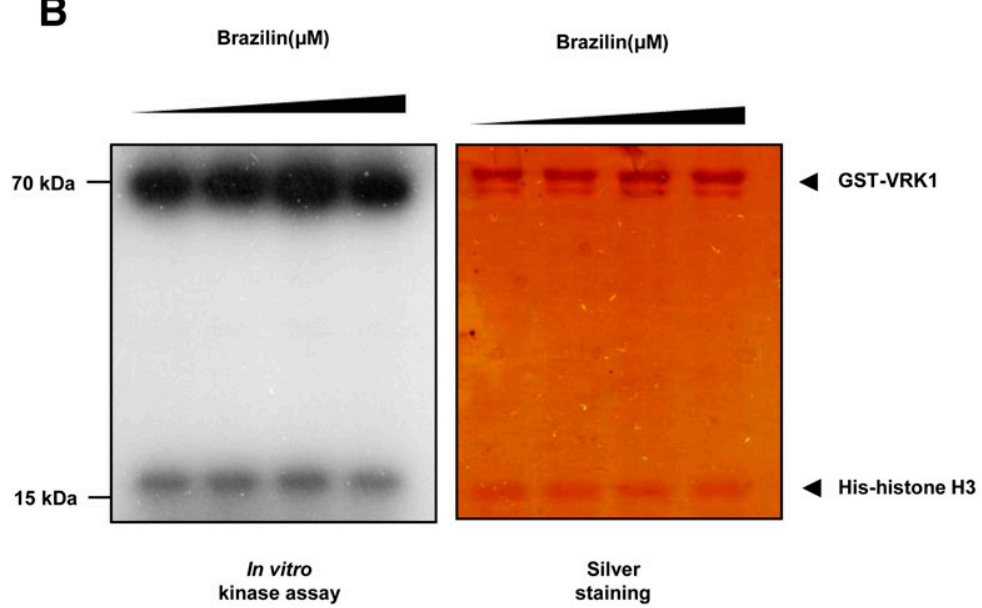

Fig. 2. Brazilin suppresses VRK1-mediated BAF phosphorylation in vitro and in vivo. (A) In vitro kinase assay in which VRK1 and BAF were exposed to increasing concentrations of brazilin $(0.0,0.3,1.0,3.0,10,30,100$, and $300 \mu \mathrm{M})$. (B) In vitro kinase assay in which VRK1 and H3 were exposed to increasing concentrations of brazilin $(0.0,3.0,10$, and $30 \mu \mathrm{M})$. Autoradiograph was performed and the proteins were silver stained (A and B). (C) Images of A549 cells treated with brazilin or DMSO. Cells were transfected with GFP-BAF or DsRed-VRK1 and stained with Hoechst. Images were acquired using confocal microscopy. Scale bars, $40 \mu \mathrm{m}$. RFP, red fluorescent protein.

et al., 2006). During the flow period, the intensity of the interaction between brazilin and BAF was assessed via signal alterations. The dissociation constant $\left(K_{\mathrm{D}}\right)$ was $38.35 \mu \mathrm{M}$, suggesting a good affinity between BAF and brazilin (Table 1).

Brazilin Disrupts Nuclear Envelope Reassembly by Inhibiting BAF Phosphorylation. BAF phosphorylation is a prerequisite for nuclear envelope reassembly during telophase (Haraguchi et al., 2008). Phosphorylation of BAF leads to its localization at the core region of the dividing chromosome, inducing the recruitment of other nuclear envelope-associated proteins, including LEM-domain proteins, lamin, and nuclear pore complex. To determine whether brazilin perturbs recruitment of nuclear envelopeassociated proteins by blocking VRK1-mediated BAF phosphorylation, we employed immunocytochemistry to observe the location of lamin during telophase. In cells treated with brazilin, lamin dispersed outside the nucleus, whereas in control cells it was located around the rim of the nucleus, as previously reported (Fig. 4A). The number of cells with lamin localization defects was 6 -fold higher in brazilin-treated cells relative to control cells (Fig. 4B). These data show that control cells progress normally from $\mathrm{M}$ phase to interphase, whereas nuclear envelope reformation is disrupted in brazilin-treated cells. Similarly, in siRNA-vrk-1 C. elegans embryos, the nuclear rim signals mAb414 and Nup96 disappear from the nuclear periphery (Gorjanacz et al., 2007).

Because nuclear envelope reformation is a final step in mitosis, failure of the nuclear envelope to reassemble could delay mitotic exit. To determine whether brazilin-mediated inhibition of lamin reformation delays mitotic progression, we observed the cell cycle distribution of A549 cells using flow cytometry. Treatment with brazilin increased the proportion of G2/M cells 1.5 -fold relative to control cells (Fig. 4, C and D).

G2/M arrest induced by brazilin in multiple myeloma U266 cells has also been observed (Kim et al., 2012). These results imply that brazilin-induced disruption of lamin localization perturbs normal cell cycle progression. In particular, brazilin disrupts recruitment of lamin to the anaphase chromatin surface, delaying mitotic progression. 


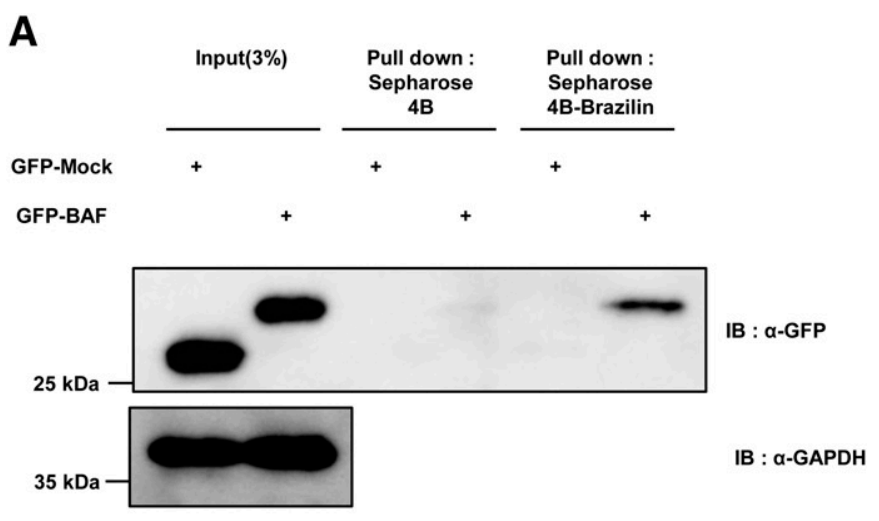

B

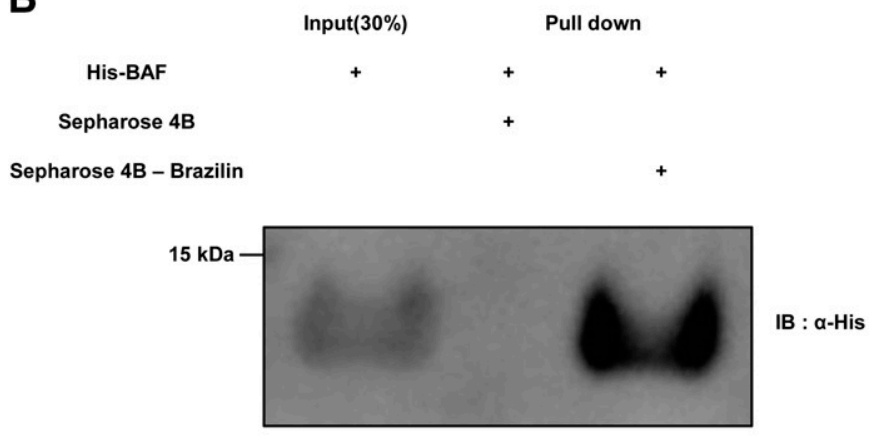

C

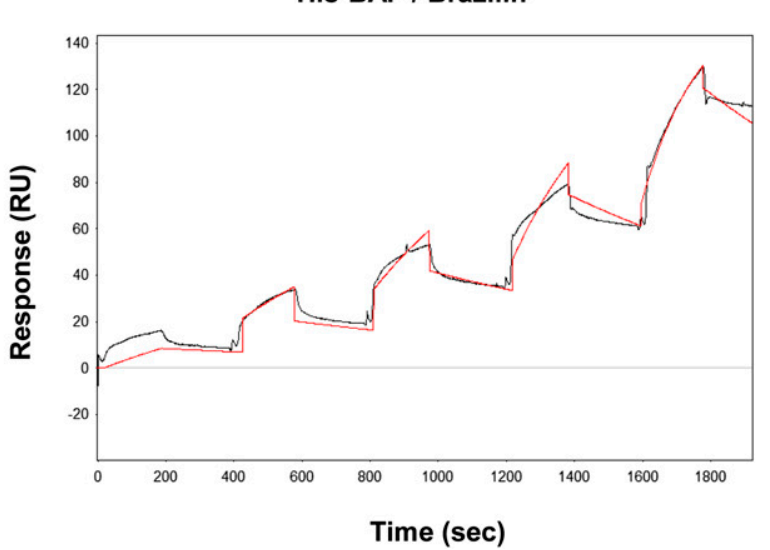

Fig. 3. Brazilin binds specifically to BAF. (A) BAF pull-down assay using brazilin-conjugated Sepharose-4B beads. A549 cells were transfected with GFP-Mock or GFP-BAF. Cell lysates were incubated with brazilin-conjugated beads or control bead. Western blotting was performed with glyceraldehyde 3-phosphate dehydrogenase (GAPDH) as the loading control. (B) Binding assay in which recombinant His-BAF was incubated with the same beads and a Western blot analysis was performed. (C) Surface plasmon resonance was performed on brazilin and recombinant His-BAF. IB, immunoblotting.

Brazilin Possesses Cytotoxicity by Inhibiting BAF Phosphorylation. A number of anticancer drugs induce mitotic arrest by activating cell cycle checkpoints, leading to cell death unless the checkpoint problems are resolved. A limitation of this protective mechanism is that cancer cells that undergo mitotic arrest can also escape via adaptation or slippage. We hypothesized that targeting mitotic exit could represent a novel strategy for overcoming this limitation, as a result of higher cytotoxicity and the failure to generate aneuploid cells. Thus, we tested whether brazilin induces cell death.
TABLE 1

Kinetic parameters of the binding of brazilin to BAF

\begin{tabular}{cccc}
\hline & $K_{\mathrm{a}}$ & $K_{\mathrm{d}}$ & $K_{\mathrm{D}}$ \\
\hline & $M^{-1} S^{-1}$ & $S^{-1}$ & $\mu M$ \\
BAF/brazilin & 4.873 & $1.869 \mathrm{e}^{-4}$ & 38.35 \\
\hline
\end{tabular}

To examine the cytotoxicity of brazilin we performed a TUNEL assay with A549 cells. Brazilin treatment dramatically decreased cell numbers and appeared to promote growth retardation as well as cell death (Fig. 5A). Additionally, we monitored cell growth using live, long-term content imaging. When $25 \mu \mathrm{M}$ brazilin was administered to $60 \%$ confluent cells, the number of cells no longer increased, and then the density decreased. These data indicate that brazilin concentrations greater than $25 \mu \mathrm{M}$ induce growth retardation, followed by cell death (Fig. 5B).

As mentioned above, brazilin-induced cell death is triggered after anaphase, when cell cycle checkpoint activation may not lead to mitotic arrest. We hypothesized that the cell death avoidance processes, such as adaptation and slippage, which result from other microtubule inhibitors, would not occur in response to brazilin. To test this hypothesis, we used flow cytometry to study these processes.

As expected, both brazilin and nocodazole, a microtubule inhibitor, induced cell death. However, when gating was used to select live cells, it became evident that nocodazole treatment increased the aneuploid cell population, indicating that mitotic slippage and adaptation were triggered after cell cycle arrest (Weaver and Cleveland, 2005). By contrast, brazilin treatment did not generate aneuploid cells, indicating that adaptation and slippage were not triggered (Fig. 5C).

These observations demonstrate that brazilin is cytotoxic to cancer cells and does not allow adaptation or slippage. The data support the idea that, rather than targeting microtubules or microtubule regulating proteins, targeting mitotic exit could represent a novel approach to cancer treatment that is attractive because it does not generate aneuploid cells.

We hypothesized that if brazilin is directly involved in inducing cell death by targeting BAF, ectopic expression of DsRed-BAF should rescue brazilin-induced cytotoxicity. Indeed, the results of the TUNEL assay showed that ectopically expressed BAF reduced brazilin-induced cell death (Fig. 5D). Thus, brazilin could induce cell death directly by targeting BAF.

Finally, we examined the anticancer effects of brazilin in a mouse model. We generated an A549-FIG cell line infected with lenti-Fluc-IRES-GFP; cell numbers were calculated by measuring fluorescence intensity (Supplemental Fig. 4A). The A549-FIG cells appeared to have proliferative abilities similar to those of normal A549 cells (Supplemental Fig. 4B), indicating that lenti-Fluc-IRES-GFP did not impair cell growth and reproduction. These cells were implanted on the ventral aspect of the mouse. Tumor volume increased in control mice but decreased in mice treated with brazilin in a concentration-dependent manner, suggesting that brazilin has anticancer effect in vivo (Fig. 5, E and F).

\section{Discussion}

We hypothesized that targeting BAF, and particularly VRK1-mediated BAF phosphorylation, would have several 
A

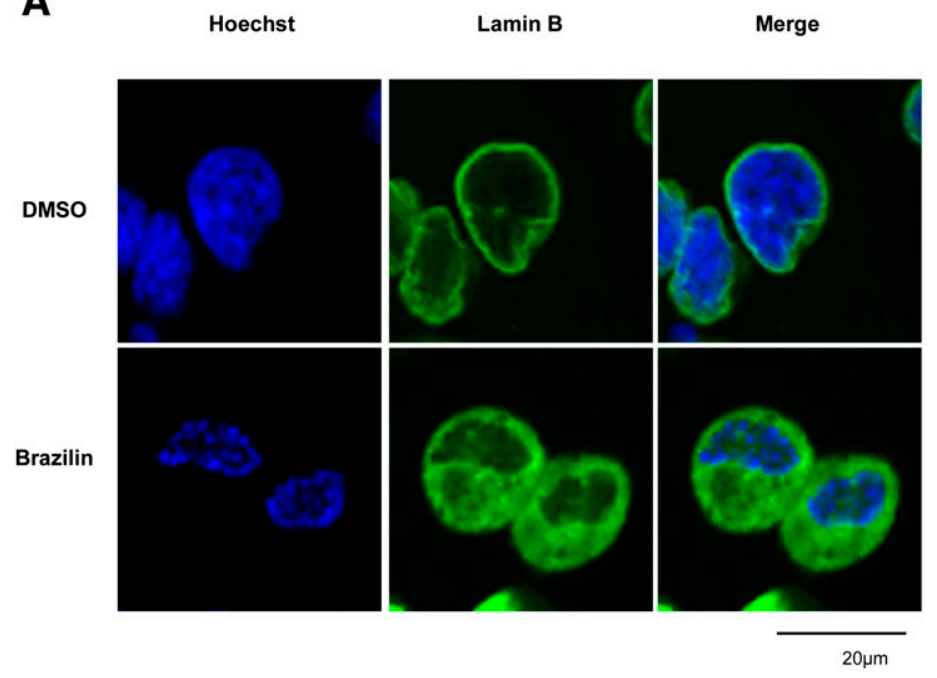

B

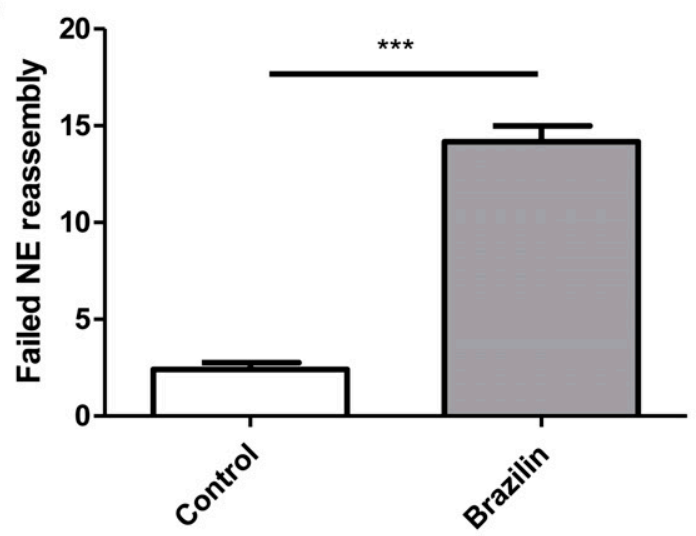

C
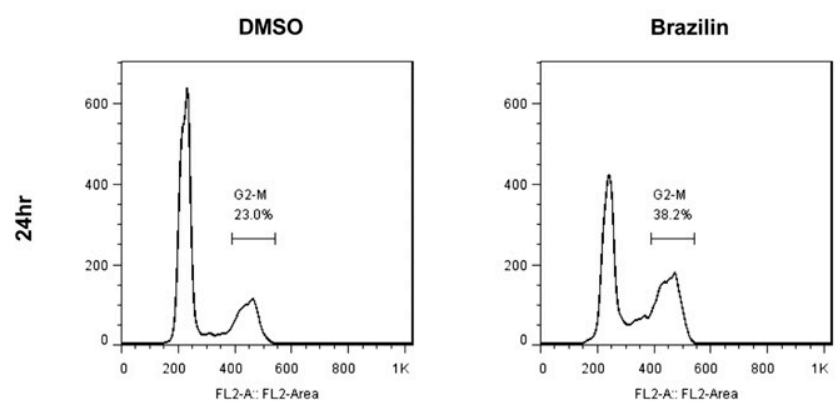

D
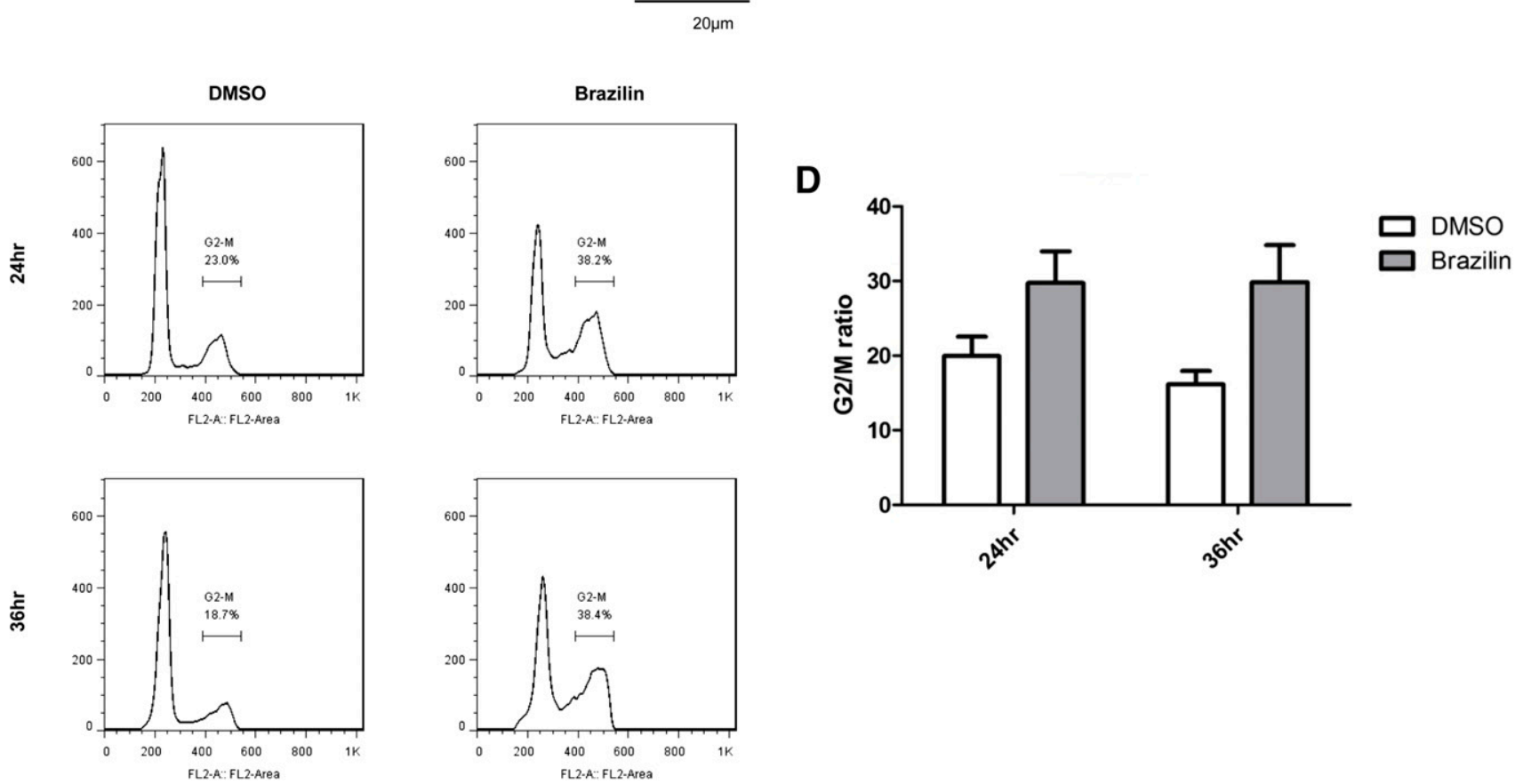

Fig. 4. Suppression of BAF phosphorylation disrupts nuclear envelope assembly. (A) Immunocytochemical staining in HeLa cells after treatment with brazilin $50 \mu \mathrm{M}$ or DMSO. Nucleus was stained with Hoechst stain and lamin B antibody. Scale bars, $20 \mu \mathrm{m}$. (B) Quantification of failed nuclear envelope reassembly in cells described in (A). Data in (B) represent the mean of three independent experiments \pm S.E.M. $P$ values were calculated using twotailed, paired Student's $t$ tests. ***P $<0.0005$. (C) Flow cytometric analysis of A549 cells treated with brazilin $100 \mu \mathrm{M}$ or DMSO. DNA was stained using propidium iodide. (D) Quantification of the proportion of cells in (C) in the G2/M stage.

benefits over targeting other mitotic kinases or microtubules. To test our hypothesis, we attempted to identify a specific inhibitor of BAF phosphorylation. We screened a library of natural compounds and isolated brazilin, a BAF inhibitor from C. sappan. We confirmed that brazilin isolated from C. sappan inhibits VRK1-mediated BAF phosphorylation in vitro and in vivo. In addition, we determined that brazilininduced BAF inhibition blocks nuclear envelope reformation during telophase, inducing cell death in cancer cells.

Brazilin has several merits as an anticancer drug. First, $\mathrm{BAF}$ is an excellent target compared with other cancer drug targets, such as microtubules or microtubule regulatory proteins. Despite reliable anticancer activity, microtubule inhibitors have severe side effects. And contrary to expectation, at tolerable concentrations, microtubule regulatory protein inhibitors investigated as a substitute for microtubule blockers have displayed weak anticancer effects (Komlodi-Pasztor et al., 2012; Mitchison, 2012).

We and other researchers expected that mitotic exit might represent an alternative target, because it would not allow cancer cells to survive via mitotic slippage or adaptation. An example in support of this hypothesis is that tumor regression is greater in response to a treatment ablating Cdc20, which activates anaphase promoting complex, than in response to other mitotic drugs currently used in cancer therapy (Manchado et al., 2010).

We selected brazilin, a BAF inhibitor, to target the end of mitosis. BAF plays a role in recruiting nuclear envelopeassociated proteins, including lamin, emerin, MAN1, and LAP2, to the chromosomal core region (Haraguchi et al., 
A

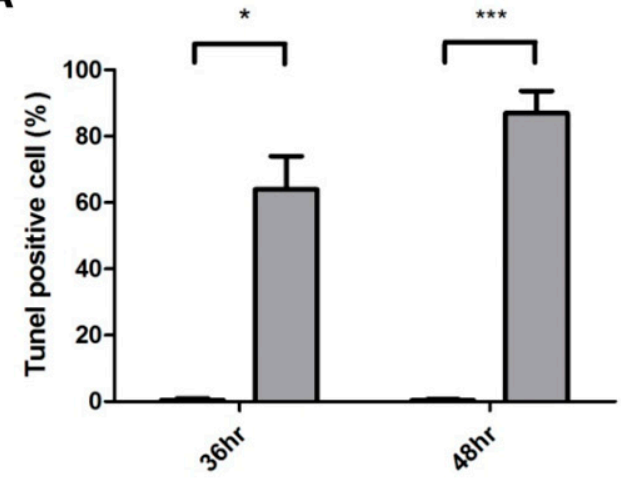

B

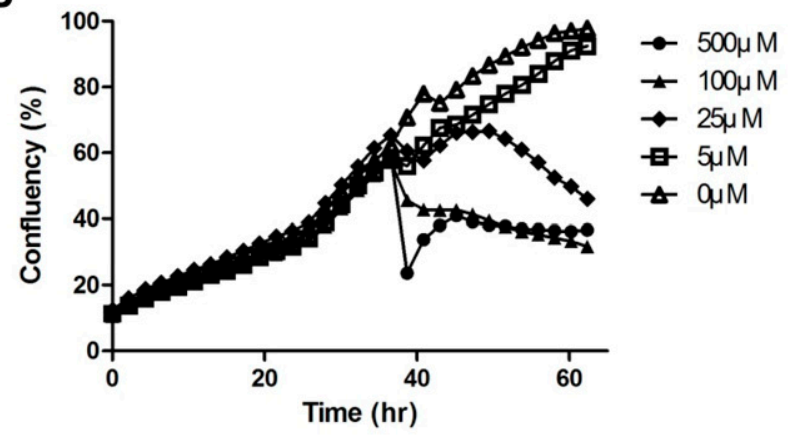

C DMSO
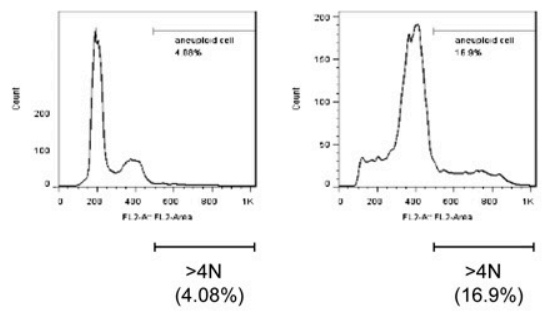

Brazilin
Control Brazilin
D

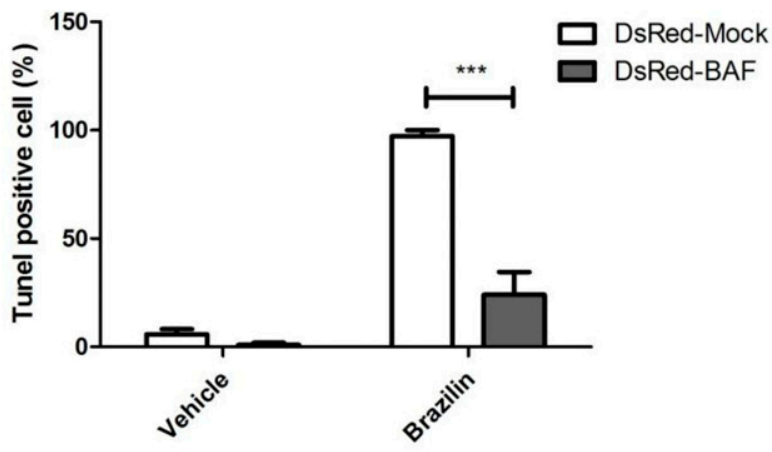

E
Vehicle

Day 0

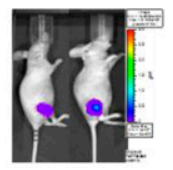

Day 7

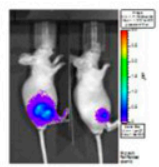

Day 14

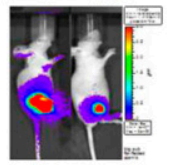

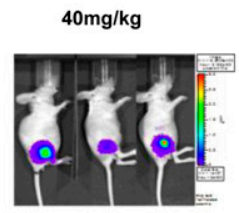

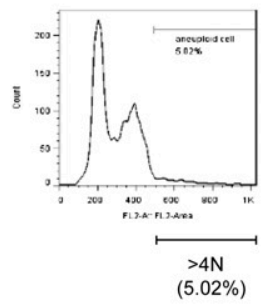

F

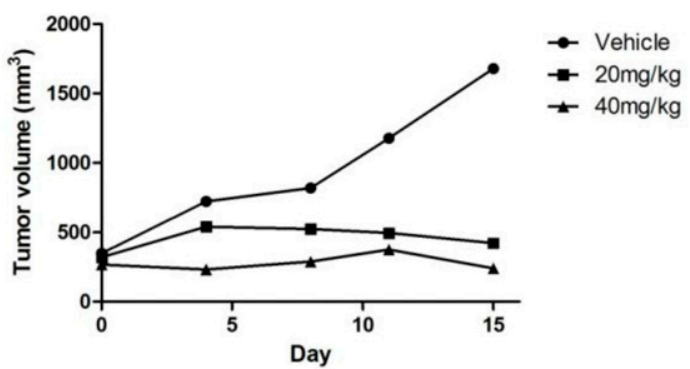

Fig. 5. Brazilin triggers cell death by suppressing BAF phosphorylation. (A) Quantification of TUNEL-positive cells in A549 cells treated with brazilin $100 \mu \mathrm{M}$ or DMSO. Fixed cells were incubated with terminal deoxynucleotidyl transferase and Hoechst stain. Data in (A) are the mean of three independent experiments \pm S.E.M. $P$ values were calculated using two-tailed, paired Student's $t$ tests. $* P<0.05$; $* * * P<0.0005$. (B) Time lapse images of a live cell using IncuCyte software (Essen BioScience, Ann Arbor, MI). (C) Flow cytometric analysis of HeLa cells treated with nocodazole $50 \mathrm{ng} / \mathrm{ml}$ or brazilin $100 \mu \mathrm{M}$. DNA was stained using propidium iodide, and DNA content in live cells was analyzed. (D) Quantification of TUNEL-positive A549 cells transfected with DsRed-BAF or DsRed-Mock. These cells were treated with or without brazilin $100 \mu \mathrm{M}$. Data in (D) are the mean of three independent experiments \pm S.E.M. $P$ values were calculated using two-tailed, paired Student's $t$ tests. ${ }^{* * *} P<0.0005$. (E) Mouse tumor size, recorded using in vivo live imaging, and (F) quantification of the size of the mouse tumors.

2008), supporting nuclear envelope reformation at mitotic exit (Haraguchi et al., 2001; Molitor and Traktman, 2014). Phosphorylation by VRK1, a novel BAF kinase, determines BAF localization during nuclear envelope reassembly (Haraguchi et al., 2008; Molitor and Traktman, 2014). Therefore, inhibition of VRK1-mediated BAF phosphorylation deserves attention in the field of cancer treatment.

Recently, it was reported that aberrant alterations of nuclear envelope components, including lamin, emerin, LAP2, and nucleoporin, are connected to cancer development (Chow et al., 2012). Cancer cells often have altered nuclear structures, including nuclear envelope invaginations and multilobulation; in fact, these features are used in the clinical diagnosis of cancers (Fischer et al., 2004; Bussolati, 2008; Bussolati et al., 2008; Petersen et al., 2009; Gorjanacz, 2014). Cancer cells are so susceptible to nuclear envelope alterations that drugs that disturb nuclear envelope distribution or reformation could easily induce cell death. Therefore, a treatment that weakens the nuclear envelope might display synthetic lethality (Gorjanacz, 2014). As BAF supports nuclear envelope structures, the depletion or altered expression of BAF results in nuclear envelope alterations (Molitor and Traktman, 2014). Therefore, targeting BAF could trigger synthetic lethality by destroying the weak nuclear envelope of cancer cells. Because depletion of VRK1 disrupts nuclear envelope morphology-consistent with the BAF mutation 
phenotype (Molitor and Traktman, 2014)—targeting VRK1 may induce synthetic lethality as well.

For these reasons, several researchers have considered the possibility of developing BAF phosphorylation inhibitors as anticancer drugs (Gorjanacz, 2014). We have reported that Obtusilactone $\mathrm{B}$, an inhibitor of $\mathrm{BAF}$ phosphorylation, perturbs detachment of chromosomes from the nuclear envelope at $\mathrm{S}$ phase and $\mathrm{M}$ phase entry, thus displaying anticancer activity (Kim et al., 2013). However, treatment with Obtusilactone B did not result in obstruction of telophase, which would be more effective. In this article, we propose that blocking mitotic exit via brazilin-induced BAF inhibition may be a good target that results in cancer cell death.

The mechanism by which brazilin binds specifically to BAF and impairs only telophase progression, but not $\mathrm{S}$ phase, remains elusive. Brazilin may directly bind the Thr-2, Thr-3, and Ser-4 residues of BAF, which are known VRK1-mediated BAF phosphorylation sites, or may act as an allosteric inhibitor of BAF by binding another site. Structure-based analysis should be performed to identify the mechanism by which brazilin inhibits BAF.

In addition, we note that brazilin could induce nuclear envelope disturbance in normal cells as well as cancer cells. Brazilin-induced disruption of nuclear envelope structures is similar to features observed in patients with progeria. In fact, a homozygous mutation in BANF1, the gene encoding BAF, has been detected in atypical progeria patients; the mutation reduces BAF stability, impairing nuclear envelope structure (Puente et al., 2011). Brazilin may accelerate aging by interfering with the nuclear envelope reassembly of normal cells. However, the probability of this occurring during cancer treatment may not be significant because in progeria the early-aging phenotype progresses over a long time period (Gorjanacz, 2014).

\section{Acknowledgments}

The authors thank Robert Craigie (US National Institutes of Health) for the gift of p-BAF antibody.

\section{Authorship Contributions}

Participated in research design: S.-H. Kim, Choi, J. Lee, K.-T. Kim. Conducted experiments: S.-H. Kim, Lyu, Y. S. Kim, Jeon, W. Kim,

S. Kim, Lim, H. W. Lee.

Contributed new reagents or analytic tools: Baek.

Performed data analysis: S.-H. Kim, Lyu, K.-T. Kim.

Wrote or contributed to the writing of the manuscript: S.-H. Kim, Lyu, Y. S. Kim, K.-T. Kim.

\section{References}

Bae IK, Min HY, Han AR, Seo EK, and Lee SK (2005) Suppression of lipopolysaccharide-induced expression of inducible nitric oxide synthase by brazilin in RAW 264.7 macrophage cells. Eur J Pharmacol 513:237-242.

Baek NI, Jeon SG, Ahn EM, Hahn JT, Bahn JH, Jang JS, Cho SW, Park JK, and Choi SY (2000) Anticonvulsant compounds from the wood of Caesalpinia sappan L. Arch Pharm Res 23:344-348.

Barr FA, Silljé HH, and Nigg EA (2004) Polo-like kinases and the orchestration of cell division. Nat Rev Mol Cell Biol 5:429-440.

Blangy A, Lane HA, d'Hérin P, Harper M, Kress M, and Nigg EA (1995) Phosphorylation by $\mathrm{p} 34 \mathrm{cdc} 2$ regulates spindle association of human Eg5, a kinesin-related motor essential for bipolar spindle formation in vivo. Cell 83:1159-1169.

Brito DA and Rieder CL (2006) Mitotic checkpoint slippage in humans occurs via cyclin B destruction in the presence of an active checkpoint. Curr Biol 16: $1194-1200$.

Bussolati G (2008) Proper detection of the nuclear shape: ways and significance. Rom J Morphol Embryol 49:435-439.

Bussolati G, Marchiò C, Gaetano L, Lupo R, and Sapino A (2008) Pleomorphism of the nuclear envelope in breast cancer: a new approach to an old problem. J Cell Mol Med 12:209-218.
Byun S, Lee KW, Jung SK, Lee EJ, Hwang MK, Lim SH, Bode AM, Lee HJ, and Dong Z (2010) Luteolin inhibits protein kinase C(epsilon) and c-Src activities and UVBinduced skin cancer. Cancer Res 70:2415-2423.

Carmena M and Earnshaw WC (2003) The cellular geography of aurora kinases. Nat Rev Mol Cell Biol 4:842-854.

Choi SY and Moon CK (1997) Effects of brazilin on the altered immune functions in the early phase of halothane intoxication of C57BL/6 mice. Planta Med 63:400-404.

Chow KH, Factor RE, and Ullman KS (2012) The nuclear envelope environment and its cancer connections. Nat Rev Cancer 12:196-209.

Cragg GM, Grothaus PG, and Newman DJ (2009) Impact of natural products on developing new anti-cancer agents. Chem Rev 109:3012-3043.

Dechat T, Gajewski A, Korbei B, Gerlich D, Daigle N, Haraguchi T, Furukawa K, Ellenberg J, and Foisner R (2004) LAP2alpha and BAF transiently localize to telomeres and specific regions on chromatin during nuclear assembly. J Cell Sci 117:6117-6128.

Dumontet C and Jordan MA (2010) Microtubule-binding agents: a dynamic field of cancer therapeutics. Nat Rev Drug Discov 9:790-803.

Fischer AH, Bardarov S, Jr, and Jiang Z (2004) Molecular aspects of diagnostic nucleolar and nuclear envelope changes in prostate cancer. $J$ Cell Biochem 91: $170-184$.

Gordaliza M (2007) Natural products as leads to anticancer drugs. Clin Transl Oncol 9:767-776.

Gorjánácz M (2014) Nuclear assembly as a target for anti-cancer therapies. Nucleus 5:47-55.

Gorjánácz M, Klerkx EP, Galy V, Santarella R, López-Iglesias C, Askjaer P, and Mattaj IW (2007) Caenorhabditis elegans BAF-1 and its kinase VRK-1 participate directly in post-mitotic nuclear envelope assembly. EMBO $J$ 26:132-143.

Haraguchi T, Kojidani T, Koujin T, Shimi T, Osakada H, Mori C, Yamamoto A and Hiraoka Y (2008) Live cell imaging and electron microscopy reveal dynamic processes of BAF-directed nuclear envelope assembly. J Cell Sci 121:2540-2554.

Haraguchi T, Koujin T, Segura-Totten M, Lee KK, Matsuoka Y, Yoneda Y, Wilson $\mathrm{KL}$, and Hiraoka Y (2001) BAF is required for emerin assembly into the reforming nuclear envelope. J Cell Sci 114:4575-4585.

Hikino H, Taguchi T, Fujimura H, and Hiramatsu Y (1977) Antiinflammatory principles of Caesalpinia sappan wood and of Haematoxylon campechianum wood Planta Med 31:214-220.

Hwang G-S, Kim J-Y, Chang T-S, Jeon S-D, So D-S, and Moon C-K (1998) Effects of Brazilin on the phospholipase A2 activity and changes of intracellular free calcium concentration in rat platelets. Arch Pharm Res 21:774-778.

Jordan MA and Wilson L (2004) Microtubules as a target for anticancer drugs. Nat Rev Cancer 4:253-265.

Karlsson R, Katsamba PS, Nordin H, Pol E, and Myszka DG (2006) Analyzing a kinetic titration series using affinity biosensors. Anal Biochem 349:136-147.

Kim B, Kim SH, Jeong SJ, Sohn EJ, Jung JH, Lee MH, and Kim SH (2012) Brazilin induces apoptosis and $\mathrm{G} 2 / \mathrm{M}$ arrest via inactivation of histone deacetylase in multiple myeloma U266 cells. J Agric Food Chem 60:9882-9889.

Kim SG, Kim YM, Khil LY, Jeon SD, So DS, Moon CH, and Moon CK (1998) Brazilin inhibits activities of protein kinase $\mathrm{C}$ and insulin receptor serine kinase in rat liver. Arch Pharm Res 21:140-146.

Kim W, Lyu HN, Kwon HS, Kim YS, Lee KH, Kim DY, Chakraborty G, Choi KY, Yoon HS, and Kim KT (2013) Obtusilactone B from Machilus Thunbergii targets barrier-to-autointegration factor to treat cancer. Mol Pharmacol 83:367-376.

Komlodi-Pasztor E, Sackett DL, and Fojo AT (2012) Inhibitors targeting mitosis: tales of how great drugs against a promising target were brought down by a flawed rationale. Clin Cancer Res 18:51-63.

Lopez-Borges S and Lazo PA (2000) The human vaccinia-related kinase 1 (VRK1) phosphorylates threonine-18 within the mdm-2 binding site of the p53 tumour suppressor protein. Oncogene 19:3656-3664.

Manchado E, Guillamot M, de Cárcer G, Eguren M, Trickey M, García-Higuera I, Moreno S, Yamano H, Cañamero M, and Malumbres M (2010) Targeting mitotic exit leads to tumor regression in vivo: Modulation by Cdk1, Mastl, and the PP2AB55 $\alpha, \delta$ phosphatase. Cancer Cell 18:641-654.

Manchado E, Guillamot M, and Malumbres M (2012) Killing cells by targeting mitosis. Cell Death Differ 19:369-377.

Mitchison TJ (2012) The proliferation rate paradox in antimitotic chemotherapy. Mol Biol Cell 23:1-6.

Mok MS, Jeon SD, Yang KM, So DS, and Moon CK (1998) Effects of Brazilin on induction of immunological tolerance by sheep red blood cells in C57BL/6 female mice. Arch Pharm Res 21:769-773.

Molitor TP and Traktman P (2014) Depletion of the protein kinase VRK1 disrupts nuclear envelope morphology and leads to BAF retention on mitotic chromosomes. Mol Biol Cell 25:891-903.

Moon C-K, Park K-S, Kim S-G, Won H-S, and Chung J-H (1992) Brazilin protects cultured rat hepatocytes from BrCCl3-induced toxicity. Drug Chem Toxicol 15: $81-91$

Nichols RJ and Traktman P (2004) Characterization of three paralogous members of the Mammalian vaccinia related kinase family. J Biol Chem 279:7934-7946.

Nichols RJ, Wiebe MS, and Traktman P (2006) The vaccinia-related kinases phosphorylate the $\mathrm{N}^{\prime}$ terminus of $\mathrm{BAF}$, regulating its interaction with DNA and its retention in the nucleus. $\mathrm{Mol}$ Biol Cell 17:2451-2464.

Park CH, Choi BH, Jeong MW, Kim S, Kim W, Song YS, and Kim KT (2011) Protein kinase $\mathrm{C} \delta$ regulates vaccinia-related kinase 1 in DNA damage-induced apoptosis. Mol Biol Cell 22:1398-1408.

Petersen I, Kotb WF, Friedrich KH, Schlüns K, Böcking A, and Dietel M (2009) Core classification of lung cancer: correlating nuclear size and mitoses with ploidy and clinicopathological parameters. Lung Cancer 65:312-318.

Puchtler H, Meloan SN, and Waldrop FS (1986) Application of current chemical concepts to metal-hematein and -brazilein stains. Histochemistry 85:353-364.

Puente XS, Quesada V, Osorio FG, Cabanillas R, Cadiñanos J, Fraile JM, Ordóñez GR, Puente DA, Gutiérrez-Fernández A, and Fanjul-Fernández M, et al. (2011) 
Exome sequencing and functional analysis identifies BANF1 mutation as the cause of a hereditary progeroid syndrome. Am J Hum Genet 88:650-656.

Rieder CL and Maiato H (2004) Stuck in division or passing through: what happens when cells cannot satisfy the spindle assembly checkpoint. Dev Cell 7:637-651.

Segura-Totten M, Kowalski AK, Craigie R, and Wilson KL (2002) Barrier-toautointegration factor: major roles in chromatin decondensation and nuclear assembly. J Cell Biol 158:475-485.

Sevilla A, Santos CR, Barcia R, Vega FM, and Lazo PA (2004a) c-Jun phosphorylation by the human vaccinia-related kinase 1 (VRK1) and its cooperation with the N-terminal kinase of c-Jun (JNK). Oncogene 23:8950-8958.

Sevilla A, Santos CR, Vega FM, and Lazo PA (2004b) Human vaccinia-related kinase 1 (VRK1) activates the ATF2 transcriptional activity by novel phosphorylation on Thr-73 and Ser-62 and cooperates with JNK. J Biol Chem 279 $27458-27465$.
Shimi T, Koujin T, Segura-Totten M, Wilson KL, Haraguchi T, and Hiraoka Y (2004) Dynamic interaction between BAF and emerin revealed by FRAP, FLIP, and FRET analyses in living HeLa cells. J Struct Biol 147:31-41.

Weaver BA and Cleveland DW (2005) Decoding the links between mitosis, cancer, and chemotherapy: the mitotic checkpoint, adaptation, and cell death. Cancer Cell 8:7-12 Won HS, Lee J, Khil LY, Chae SH, Ahn MY, Lee BH, Chung JH, Kim YC, and Moon CK (2004) Mechanism of action of Brazilin on gluconeogenesis in isolated rat hepatocytes. Planta Med 70:740-744.

Address correspondence to: Kyong-Tai Kim, Division of Integrative Biosciences and Biotechnology, POSTECH, Hyojadong, Pohang, Gyeongbuk, South Korea. E-mail: ktk@postech.ac.kr 